\title{
Long-term outcomes of stereotactic body radiation therapy (SBRT) with fiducial tracking for inoperable stage I non-small cell lung cancer (NSCLC)
}

\author{
Jonathan W. Lischalk ${ }^{1}$ - Stephanie M. Woo ${ }^{1} \cdot$ Shaan Kataria $^{1}$ - Nima Aghdam ${ }^{1}$. \\ Ima Paydar ${ }^{1}$. Michael C. Repka ${ }^{1}$ Eric D. Anderson ${ }^{2} \cdot$ Brian T. Collins $^{1}$
}

Received: 3 June 2016 / Accepted: 10 August 2016 /Published online: 20 August 2016

(C) The Author(s) 2016. This article is published with open access at Springerlink.com

\begin{abstract}
Background Stereotactic body radiation therapy (SBRT) for stage I non-small cell lung cancer (NSCLC) is considered standard of care in the medically inoperable patient population. Multiple methods of SBRT delivery exist

Preliminary and partial results of this study were presented at the following: (1) American College of Chest Physicians (CHEST) World Congress 2014 in Madrid, Spain from March 21st to 24th, 2014, and (2) Annual American College of Chest Physicians (CHEST) conference Chest 2014 in Austin, Texas from October $25^{\text {th }}$ to $30^{\text {th }}, 2014$.
\end{abstract}

Jonathan W. Lischalk

jonathan.lischalk@gunet.georgetown.edu

Stephanie M. Woo

sw728@georgetown.edu

Shaan Kataria

shaan.k.kataria@gunet.georgetown.edu

Nima Aghdam

nima.aghdam@gunet.georgetown.edu

Ima Paydar

ima.paydar@gunet.georgetown.edu

Michael C. Repka

michael.c.repka@gunet.georgetown.edu

Eric D. Anderson

andersoe@gunet.georgetown.edu

Brian T. Collins

COLLINSB@gunet.georgetown.edu

1 Department of Radiation Medicine, Georgetown University Hospital, Lower Level Bles, 3800 Reservoir Road, N.W, Washington, DC 20007, USA

2 Division of Pulmonary, Critical Care, and Sleep Medicine, Georgetown University Hospital, Pasquerilla Healthcare Center, 5th floor, 3800 Reservoir Road, N.W., Washington, DC 20007, USA including fiducial-based tumor tracking, which allows for smaller treatment margins and avoidance of patient immobilization devices. We explore the long-term clinical outcomes of this novel fiducial-based SBRT method.

Methods In this single institutional retrospective review, we detail the outcomes of medically inoperable pathologically confirmed stage I NSCLC. Patients were treated with the Cyberknife SBRT system using a planning target volume (PTV) defined as a 5-mm expansion from gross tumor volume (GTV) without creation of an internal target volume (ITV). Dose was delivered in three or five equal fractions of 10 to 20 Gy. Pretreatment and posttreatment pulmonary function test (PFT) changes and evidence of late radiological rib fractures were analyzed for the majority of patients. Actuarial local control, locoregional control, distant control, and overall survival were calculated using the Kaplan-Meier method. Results Sixty-one patients with a median age of 75 years were available for analysis. The majority $(80 \%)$ of patients were deemed to be medically inoperable due to underlying pulmonary dysfunction. Eleven patients (18\%) developed symptomatic pneumothoraces secondary to fiducial placement under CT guidance, which precipitously dropped to $0 \%$ following transition to bronchoscopic fiducial placement. The 2-year rib fracture risk was $21.4 \%$ with a median time to rib fracture of 2.9 years. PFTs averaged over all patients and parameters demonstrated small absolute declines, 5.7 \% averaged PFT decline, at approximately 1 year of follow-up, but only the diffusing capacity of lung for carbon monoxide $\left(\mathrm{DL}_{\mathrm{CO}}\right)$ demonstrated a statistically significant decline $(10.29$ vs. $9.01 \mathrm{~mL} / \mathrm{min} / \mathrm{mmHg}$, $p=0.01)$. Five-year local control, locoregional control, and overall survival were 87.6, 71.8, and $39.3 \%$, respectively.

Conclusions Despite reduced treatment margins and lack of patient immobilization, SBRT with fiducial-based tumor tracking achieves clinically comparable long-term outcomes to other linac-based SBRT approaches. 
Keywords Lung neoplasms • Non-small cell lung cancer . Stereotactic body radiation therapy $\cdot$ Pulmonary function test . Fiducial markers

$\begin{array}{ll}\text { Abbreviations } \\ \text { BED } & \text { Biological effective dose } \\ \text { DL } & \text { Diffusing capacity of lung for carbon monoxide } \\ \text { FEV } & \text { Forced expiratory volume } \\ \text { FVC } & \text { Forced vital capacity } \\ \text { GTV } & \text { Gross tumor volume } \\ \text { IDL } & \text { Isodose line } \\ \text { NSCLC } & \text { Non-small cell lung cancer } \\ \text { PTV } & \text { Planning target volume } \\ \text { SBRT } & \text { Stereotactic body radiation therapy } \\ \text { TLC } & \text { Total lung capacity }\end{array}$

\section{Introduction}

The 2016 incidence of newly diagnosed lung cancer is estimated to be 224,390 with approximately 158,080 of these patients succumbing to their disease [1]. Lung cancer continues to be the leading cause of cancer-related death for both men and women in the United States and is the leading cause of cancer death worldwide, accounting for $18 \%$ of all cancerrelated deaths [2-4]. Non-small cell lung cancer (NSCLC) comprises the vast majority of cases $(\sim 85 \%)$, with adenocarcinoma being the most common histologic subtype [5]. Unfortunately, the majority of patients are diagnosed with metastatic disease at presentation [2]. These abysmal statistics prompted the National Lung Screening Trial Research Team to explore the utility of low-dose computed tomographic (CT) screening in a high-risk population [6]. The results demonstrated low-dose CT screening yielded a $20 \%$ relative reduction in mortality from lung cancer and a $6.7 \%$ relative reduction in all-cause mortality [6]. These practice changing results prompted the US Preventive Services Task Force in 2013 to recommend annual screening for lung cancer with low-dose CT scans in patients aged 55 to 80 with a 30 pack-year smoking history who are current smokers or quit within the past 15 years [7]. As implementation of these new screening guidelines becomes ubiquitous, an increase in the incidence of early-stage NSCLC is plausible.

The current National Comprehensive Cancer Network (NCCN) standard of care for medically operable stage I NSCLC continues to be anatomical surgical resection, preferably a lobectomy. Increasing proportions, estimated at $25 \%$ of patients, however, are considered inoperable either due to advanced age or significant medical comorbidities precluding thoracic surgery [8]. Historically, conventionally fractionated radiotherapy yielded low rates of overall survival of approximately $15 \%$ and widely variable local control ranging from 30 to $70 \%[8,9]$. However, the development of stereotactic body radiation therapy (SBRT) as a treatment alternative to conventional fractionation led to the landmark phase II RTOG 0236 trial, which demonstrated a marked improvement in 3-year local control and overall survival of 98 and $56 \%$, respectively [10].

A number of modalities of SBRT delivery have since been established, including one unique modality, which utilizes fiducial-based tumor tracking. This technique uses gold markers placed by an interventional pulmonologist within or directly adjacent to the tumor to monitor lesion movement with respiration using periodically obtained $\mathrm{x}$-rays during treatment. The non-isocentric robotic stereotactic system allows for highly conformal dose distributions with rapid dose fall off, permitting treatment margin reduction and thus minimizing delivery of excess dose to adjacent normal tissues [11, 12]. The aggregate result is a minimization of excess dose to adjacent lung parenchyma, heart, and esophagus as well as avoidance of burdensome patient immobilization devices during treatment. Since 2005, our institution has treated patients with this image-guided fiducial-based SBRT technique utilizing continuous tracking of tumor motion $[11,12]$. In this retrospective analysis, we investigate clinical outcomes of patients with stage I NSCLC from a single institution treated with robotically delivered fiducial-based SBRT.

\section{Materials and methods}

\section{Patient eligibility}

The local Health Research Institutional Review Board (IRB) approved this retrospective analysis of an established departmental treatment approach. Inclusion criteria for this investigation included (1) pathologic confirmation of NSCLC malignancy, (2) American Joint Committee on Cancer (AJCC) seventh edition stage I (cT1a to cT2a) disease, (3) pretreatment staging PET/CT scan, (4) acceptable fiducial placement for safe SBRT delivery as determined by the attending radiation oncologist, and (5) medical inoperability determined by a single pulmonologist (EDA). In general, patients were deemed medically inoperable if they demonstrated preoperative forced expiratory volume (FEV1) $<40 \%$ of predicted value, diffusing capacity of lung for carbon monoxide $\left(\mathrm{DL}_{\mathrm{CO}}\right)<40 \%$ of predicted value, very poor exercise tolerance, and/or significant underlying cardiac disease. However, operability was determined on a case-by-case basis. Exclusion criteria included (1) prior history of malignancy within the last 5 years, (2) prior thoracic radiation, (3) prior systemic therapy, and (4) identification of any other suspicious pulmonary nodules. All patients were evaluated and underwent placement of 
fiducials via $\mathrm{CT}$ guidance or electromagnetic navigational bronchoscopy within or directly adjacent to the tumor.

\section{Treatment planning and delivery}

A fine-cut treatment planning CT scan was obtained in the supine treatment position for each patient using a LightSpeed RT16 (GE Healthcare, Little Chalfont, United Kingdom). Full-inhalation CT scans were obtained with intravenous contrast, oral contrast, and/or esophageal paste when clinically indicated. PET/CT scans, requisite for study inclusion, were obtained for staging and treatment planning purposes. The gross tumor volume (GTV) was contoured using lung window settings and with input from the attending pulmonologist. A 5-mm expansion was added to the GTV to generate a planning target volume (PTV). Of note, the CyberKnife Synchrony System (Cyberknife, Sunnyvale, CA, USA) of intrafractional tumor motion tracking precluded the creation of an internal target volume (ITV). A treatment plan was generated using the MultiPlan 5.2.1 non-isocentric inverse-planning algorithm. Radiation was delivered in three or five equal fractions of 10 to 20 Gy prescribed to an isodose line that covered at least $95 \%$ of the PTV. All dose fractionation schedules were assured to deliver a biological effective dose (BED) of at least 100 Gy using an NSCLC tumor $\alpha / \beta$ of $10 \mathrm{~Gy}$. Patients were treated in the supine position with arms at their sides without immobilization device utilization. The Synchrony Respiratory Motion Tracking System was used to accommodate for patient-specific respiratory motion during treatment $[11,13]$. Treatment was typically delivered over consecutive days, usually over one week and not exceeding two weeks.

\section{Follow-up}

Patients were followed with physical examination and CT with or without PET imaging at 3-to 6-month intervals per routine institutional practice. Pulmonary function tests (PFTs) were obtained for the majority of patients before and after radiotherapy. Post-treatment PFTs were obtained at least 90 days following radiotherapy and if possible, at approximately one year of follow-up. PFT paired comparisons were made only on patients with available pre-treatment and posttreatment PFTs. Follow-up CT scans were used to detect radiological rib fractures and were reviewed by two radiation oncologists (BTC and JWL). Local tumor recurrence was defined as documented tumor progression within the treated field (i.e. in-field failures) as evaluated on follow-up imaging. Locoregional failure was defined as any failure within the treated field, involved lobe, or ipsilateral nodal region (N1 to N2). Each recurrence was reviewed and confirmed by the same two radiation oncologists (BTC and JWL). Local control, locoregional control, and distant control were measured from the date of treatment completion to the date of last radiological follow-up, radiological progression, or death. Patients who were alive without failure were censored at the date of last radiological follow-up. Overall survival was measured from the date of treatment completion to the date of patient death.

\section{Statistical analysis}

Statistical analysis was performed with the IBM SPSS Statistics version 22 (IBM Corporation and other(s) 1989, 2013, Armonk, NY, USA). Comparison of paired cohort-averaged PFT changes before and after radiotherapy was performed using the Wilcoxon signed rank test. Actuarial local control, locoregional control, distant control, and overall survival were calculated using the Kaplan-Meier method. Univariate analysis of factors affecting local control, locoregional control, distant control, and overall survival were determined using generalized Wilcoxon analysis.

\section{Results}

\section{Patient and tumor characteristics}

Sixty-one patients with a median age of 75 years (range, 59 to 94 years) were treated from August 2005 to September 2015. The vast majority of patients attested to a history of tobacco use $(93 \%)$ with a median packyear smoking history of 41.0. Of those with a smoking history, $77 \%$ were classified as former smokers and $23 \%$ as current smokers. Surgical inoperability was primarily due to prohibitive pulmonary dysfunction in $80 \%$ of cases with the remainder due to advanced age and/or other medical comorbidities. In fact, $31 \%$ of all patients had baseline oxygen dependency. The majority of tumors were located within the left upper lobe (30\%) and right upper lobe $(26 \%)$. The mean maximum tumor diameter on pretreatment CT scan was measured to be $2.5 \mathrm{~cm}$ (range, 0.9 to $5.0 \mathrm{~cm}$ ). The majority of tumors treated were AJCC seventh edition prognostic stage IA (75\%). Median tumor $\mathrm{SUV}_{\text {max }}$ on pretreatment PET scan was 5.7. Specific patient and tumor characteristics are shown in Tables 1 and 2.

\section{Treatment characteristics}

Thirty-two patients $(52 \%)$ underwent placement of fiducials via electromagnetic navigational bronchoscopy with the remaining 29 (48\%) under CT guidance. Three to four fiducials were placed in the majority $(81 \%)$ of cases. The number of fiducials placed was at the 
Table 1 Patient characteristics

\begin{tabular}{|c|c|c|}
\hline Characteristic & No. of patients & Percent \\
\hline \multicolumn{3}{|l|}{ Age } \\
\hline$\leq 75$ & 31 & 51 \\
\hline$>75$ & 30 & 49 \\
\hline \multicolumn{3}{|l|}{ Gender } \\
\hline Male & 20 & 33 \\
\hline Female & 41 & 67 \\
\hline \multicolumn{3}{|l|}{ ECOG performance status } \\
\hline 0 & 4 & 7 \\
\hline 1 & 28 & 46 \\
\hline 2 & 22 & 36 \\
\hline 3 & 7 & 11 \\
\hline \multicolumn{3}{|l|}{ Smoking status } \\
\hline Never & 4 & 7 \\
\hline Former & 44 & 72 \\
\hline Current & 13 & 21 \\
\hline \multicolumn{3}{|l|}{ Tobacco history (pack-years) } \\
\hline 0 & 4 & 7 \\
\hline$<40$ & 20 & 33 \\
\hline $40-50$ & 21 & 34 \\
\hline$>50$ & 16 & 26 \\
\hline \multicolumn{3}{|l|}{ Baseline oxygen dependence } \\
\hline Yes & 19 & 31 \\
\hline No & 42 & 69 \\
\hline \multicolumn{3}{|l|}{ Reason for inoperability } \\
\hline Age & 11 & 18 \\
\hline Pulmonary dysfunction & 49 & 80 \\
\hline Other medical comorbidities & 1 & 2 \\
\hline
\end{tabular}

discretion of the interventional pulmonologist with the understanding that a minimum of three fiducials was required for rotational tracking. Patients were treated using the CyberKnife robotic radiosurgical system to a median total dose of $50 \mathrm{~Gy}$ (range, 45 to $60 \mathrm{~Gy}$ ) with a median BED of 112.5 Gy (range, 100.0 to 180.0 Gy). The median number of treatment fractions and dose per fraction was 5 (range, 3 to 5) and $11 \mathrm{~Gy} /$ fraction (range, 10 to $20 \mathrm{~Gy} /$ fraction), respectively. Median treatment duration from start to completion of SBRT was 7 days (range, 3 to 15 days). Mean and median GTV was 17.8 and $13.4 \mathrm{cc}$ (range, 1.3 to $62.2 \mathrm{cc}$ ), respectively. Treatment was delivered to a median prescription isodose line of $79 \%$ with a median PTV target coverage of $99 \%$. Specific treatment characteristics are shown in Table 3.

\section{Treatment toxicity}

Pneumothoraces requiring chest tube placement occurred in 11 patients $(18 \%)$, all of which were secondary to fiducial placement under CT guidance. This
Table 2 Tumor characteristics

\begin{tabular}{lll}
\hline Characteristic & No. of patients & Percent \\
\hline Histology & & \\
$\quad$ Adenocarcinoma & 30 & 49 \\
$\quad$ Squamous cell carcinoma & 16 & 26 \\
$\quad$ Unspecified NSCLC & 15 & 25 \\
Tumor max diameter (cm) & & \\
$\quad<2$ & 20 & 33 \\
$\quad 2-3$ & 26 & 43 \\
$\quad 3-5$ & 15 & 24 \\
AJCC prognostic stage & & \\
IA & 46 & 75 \\
IB & 15 & 25 \\
PET max SUV & & \\
$\quad<4$ & 19 & 31 \\
$4-10$ & 28 & 46 \\
$>10$ & 13 & 23 \\
Tumor lobe location & & 26 \\
RUL & 16 & 2 \\
RML & 1 & 18 \\
RLL & 11 & 30 \\
LUL & 18 & 24 \\
LLL & 15 & \\
\hline
\end{tabular}

high rate of pneumothoraces prompted an institutional shift to utilize bronchoscopy for fiducial placement in

Table 3 Treatment characteristics

\begin{tabular}{lll}
\hline Characteristic & No. of patients & Percent \\
\hline $\begin{array}{l}\text { Fiducial placement technique } \\
\text { CT guided }\end{array}$ & 29 & 48 \\
Bronchoscopic & 32 & 52 \\
Number of fiducials placed & & \\
2 & 7 & 11 \\
3 & 26 & 43 \\
4 & 23 & 38 \\
Other & 5 & 8 \\
PTV volume (cc) & & \\
$<30$ & 25 & 41 \\
$30-60$ & 24 & 39 \\
$>60$ & 12 & 20 \\
Total dose (Gy)/number of fractions & \\
$60 / 3$ & 5 & 8 \\
$45 / 3$ & 9 & 15 \\
$54 / 3$ & 8 & 13 \\
$50 / 5$ & 30 & 49 \\
$60 / 5$ & 3 & 5 \\
Other & 6 & 10 \\
\hline
\end{tabular}


the latter half of the study duration. There were subsequently no chest tube placements observed following the adoption of bronchoscopic fiducial placement in this cohort. Relative to CT-guided fiducial placement, electromagnetic-navigated bronchoscopic placement of fiducials resulted in minimal acute toxicity. Although cough and hemoptysis are not uncommon following bronchoscopy, the available medical records incompletely addressed these low-grade toxicities. A total of 19 rib fractures were identified on radiological followup. Each rib fracture was confirmed to be adjacent to or within the SBRT treatment field. The median time to rib fracture was 2.9 years with an estimated 2-year rib fracture risk of $21.4 \%$. In those patients with follow-up greater than 3.2 years, the rib fracture risk appeared to plateau, as no new radiological rib fractures were identified.

PFTs were performed and available for our analysis on 56 patients $(92 \%)$ prior to and 47 patients (77\%) following radiotherapy treatment. Pretreatment PFTs were obtained at a median of 56 days prior to SBRT; posttreatment PFTs were obtained at a median of 368 days following radiotherapy. Cohort-averaged FEV1, forced vital capacity (FVC), and $\mathrm{DL}_{\mathrm{CO}}$ all demonstrated modest absolute decreases following radiotherapy treatment. However, $\mathrm{DL}_{\mathrm{CO}}$ demonstrated the only statistically significant decrease following SBRT treatment ( 10.3 vs. $9.0 \mathrm{~mL} / \mathrm{min} / \mathrm{mmHg}, p=0.01)$. Cohortaveraged pulmonary function tests performed prior to and following radiotherapy are detailed in Table 4.

\section{Local control and overall survival}

The 3- and 5-year Kaplan-Meier local control was 91.1 and $87.6 \%$, respectively (Fig. 1a). Four local recurrences were observed with a mean time to local recurrence of 2.6 years. Of note, in those patients who recurred locally,

Table 4 Pulmonary function test changes

\begin{tabular}{lllll}
\hline Characteristic & $\begin{array}{l}\text { Mean } \\
\text { pretreatment }\end{array}$ & $\begin{array}{l}\text { Mean } \\
\text { posttreatment }\end{array}$ & $\begin{array}{l}\text { Median } \\
\text { change }\end{array}$ & $\begin{array}{l}p \\
\text { value }\end{array}$ \\
\hline FEV1 & & & & \\
$\quad$ Liters & 1.26 & 1.18 & -0.05 & 0.46 \\
$\quad \%$ predicted & 56.8 & 55.0 & -5 & 0.71 \\
FVC & & & & \\
$\quad$ Liters & 2.29 & 2.07 & -0.06 & 0.45 \\
$\quad \%$ predicted & 77.8 & 76.7 & -3 & 0.47 \\
$\begin{array}{l}\text { DLCO } \\
\text { mL/min/mmHg }\end{array}$ & 10.29 & 9.01 & -1.25 & 0.01 \\
$\quad \%$ predicted & 53.5 & 52.1 & -10 & 0.10 \\
$\begin{array}{l}\text { TLC } \\
\quad \text { Liters }\end{array}$ & 5.63 & 5.67 & -0.25 & 0.36 \\
$\quad \%$ predicted & 111 & 134 & -5 & 0.75 \\
\hline
\end{tabular}
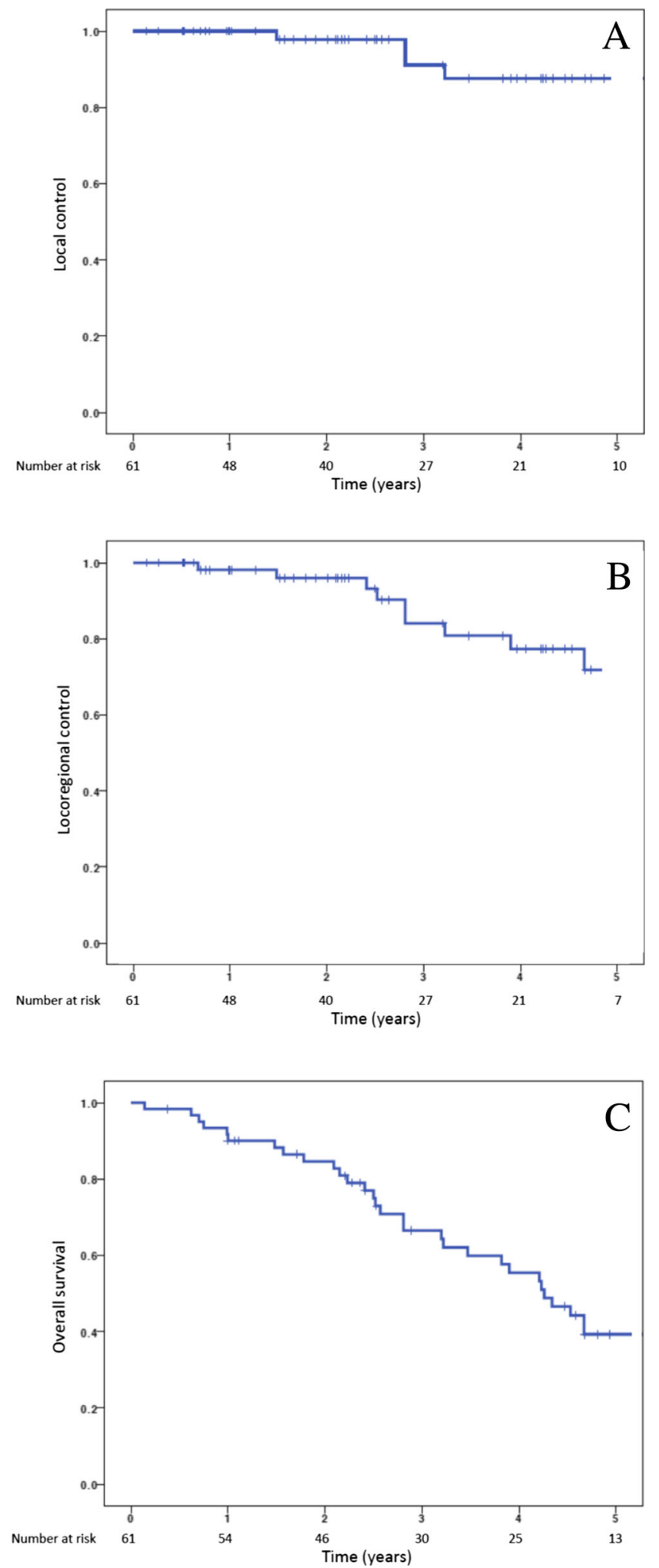

Fig. 1 a Kaplan-Meier local control. b Kaplan-Meier locoregional control. c Kaplan-Meier overall survival

progressive local disease was eventually determined to be the cause of death in all four patients. Kaplan-Meier 3and 5-year locoregional control was 84.1 and $71.8 \%$, 
respectively (Fig. 1b). Only one involved lobe non-local failure was observed. A total of four ipsilateral nodal failures were identified with a mean time to nodal failure of 2.4 years following treatment. At the time of analysis, three patients with regional failures had died; two patients went on to die of progressive metastatic disease, and the remaining death was due to progressive COPD.

The 3- and 5-year Kaplan-Meier distant control rate was 95.8 and $79.5 \%$, respectively. Of note, a total of six patients developed metastatic disease as the site of first treatment failure. A total of five patients eventually developed metachronous primaries, which included three lung, one pancreatic, and one gynecologic. The 3- and 5 -year Kaplan-Meier overall survival was 66.6 and $39.3 \%$, respectively (Fig. 1c). The median KaplanMeier overall survival was estimated to be 4.3 years. Univariate analysis demonstrated squamous cell histology to be the only statistically significant predictor of local failure. Locoregional failure was significantly associated with ECOG performance status $\geq 2$ and tumor size $>2.5 \mathrm{~cm}$. Only ECOG performance status $\geq 2$ and tumor size $>2.5 \mathrm{~cm}$ were associated with a decrement in overall survival. The patient population was undersized to detect statistically significant differences on multivariate analysis. Univariate analysis is detailed in Table 5.

Table 5 Univariate analysis

\begin{tabular}{lllll}
\hline Parameter & LC & LRC & DC & OS \\
& $p$ & $p$ & $p$ & $p$ \\
\hline $\begin{array}{l}\text { Sex } \\
\quad \text { Male vs. female }\end{array}$ & 0.70 & 0.44 & 0.19 & 0.70 \\
$\begin{array}{l}\text { Age (years) } \\
\quad>75 \text { vs. } \leq 75\end{array}$ & 0.23 & 0.19 & 0.19 & 0.29 \\
$\begin{array}{l}\text { ECOG } \\
\quad \geq 2 \text { vs. }<2\end{array}$ & 0.08 & $0.004^{\mathrm{a}}$ & 0.13 & $0.03^{\mathrm{a}}$ \\
$\begin{array}{l}\text { Tobacco (pack-years) } \\
\quad>40 \text { vs. } \leq 40\end{array}$ & 0.41 & 0.06 & 0.96 & 0.31 \\
$\begin{array}{l}\text { Tumor size (cm) } \\
\quad>2.5 \text { vs. } \leq 2.5 \text { cm }\end{array}$ & 0.23 & $0.04^{\mathrm{a}}$ & 0.32 & $0.01^{\mathrm{a}}$ \\
$\begin{array}{l}\text { PET SUV } \\
\quad>6 \text { vs. } \leq 6\end{array}$ & & & & \\
$\begin{array}{l}\text { Histology } \\
\quad \text { Squamous vs. others }\end{array}$ & $0.003^{\mathrm{a}}$ & 0.30 & 0.76 & 0.54 \\
$\begin{array}{l}\text { Tumor location } \\
\quad \text { Lower vs. upper lobe }\end{array}$ & 0.45 & 0.30 & 0.26 & 0.50 \\
$\begin{array}{l}\text { PTV (cc) } \\
>50 \text { vs. } \leq 50\end{array}$ & 0.72 & 0.95 & 0.46 & 0.10 \\
\hline
\end{tabular}

LC local control, $L R C$ locoregional control, $D C$ distant control, $O S$ overall survival

${ }^{\text {a }}$ Statistically significant results

\section{Discussion}

Image-guided robotic SBRT with fiducial-based tracking is an innovative method of treating stage I NSCLC that allows for treatment beam movement in concert with patient respiratory motion, yielding extremely accurate dose delivery (Fig. 2 illustrates a fiducial-based SBRT plan). This allows for treatment margin reduction and minimization of radiation exposure to normal tissues including the lung, heart, and esophagus [14, 15]. This margin reduction comes without cumbersome patient immobilization devices used with other linac-based SBRT systems, which can be difficult to tolerate for patients with underlying pulmonary dysfunction and other medical comorbidities [15]. Our results are similar to those reported in the RTOG 0236 with 3 -year primary local control rates and locoregional control rates of 91.1 versus $97.6 \%$ and 84.1 versus $87.2 \%$, respectively [10]. Interestingly, the 5-year results of RTOG 0236 demonstrate continued excellent primary tumor control of $93 \%$ but appreciably lower locoregional control of $62 \%$ [16]. This is in contrast with our 5-year results showing a lower primary tumor local control of $87.6 \%$ but higher locoregional control of $71.8 \%$.

Intriguingly, the results of the present study demonstrate a very low lobar failure rate with only one involved lobe recurrence observed during the follow-up period. The first explanation for these low in-lobe failure rates may be the result of differences in dose distribution, including possible variations in isodose line prescription. Indeed, inclusion of $\mathrm{CT}$ identified

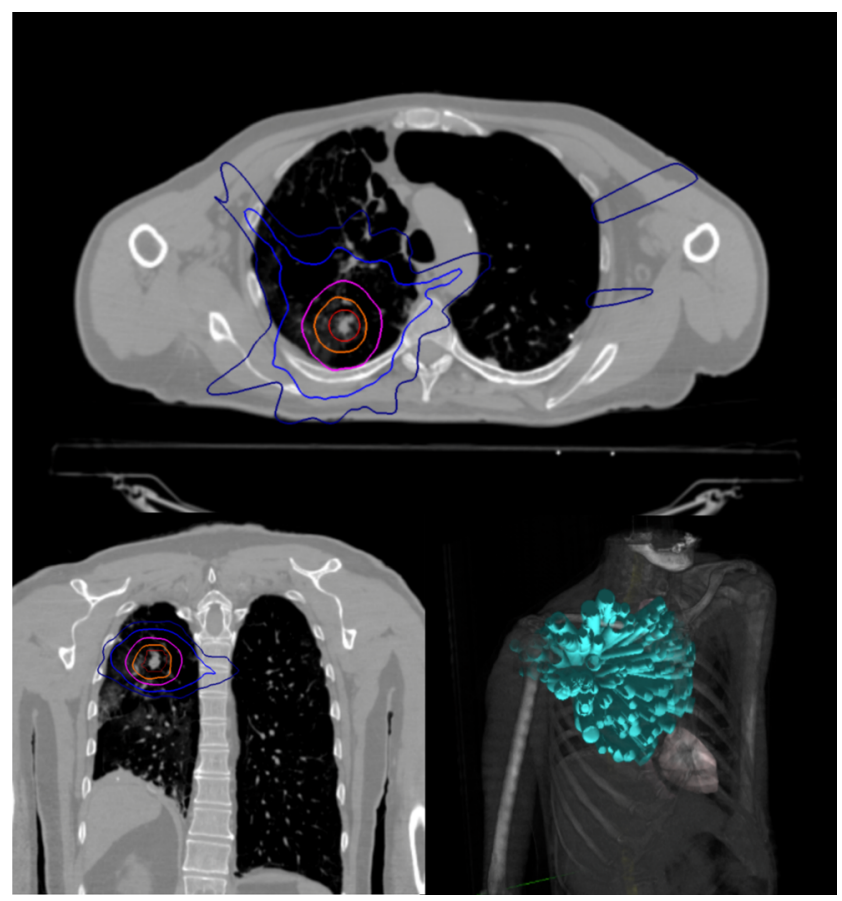

Fig. 2. SBRT example plan for stage I NSCLC 
spiculations within the treatment field is variable, dependent on the oncologist/institution, and could result in differences in involved-lobe failure rates [17]. As a result, differences in dose fall off in this region may adequately sterilize microscopic spread within these spiculations and are incumbent upon the isodose line chosen. Second, utilization of intrafractional tumor tracking could allow for more accurate dose delivery to the tumor during treatment. The third explanation may be our careful exclusion of patients with additional concerning pulmonary nodules, which may incidentally be located in the involved lobe and eventually declare themselves as malignant. The fourth and perhaps most interesting reason for our low involved-lobe failure rate resides in the simplification of radiological follow-up due to the presence of fiducials. Post-SBRT pulmonary fibrosis can be quite substantial and often obscures the location of the initially treated primary lesion [18]. Fiducial marking of the treated tumor allows for accurate identification of the treated field on follow-up imaging, which is not feasible in other non-fiducial-based SBRT methods. As a result, the radiologist may more easily differentiate local recurrences from involved lobe failures.

Fiducial placement, however, does not come without risk. As we report, there were notably more symptomatic pneumothoraces observed early on in this study when the majority of patients underwent fiducial placement with CT guidance. Eleven of 29 (38\%) patients who underwent CT-guided fiducial placement developed symptomatic pneumothoraces requiring chest tube placement. Kothary et al. reported pneumothoraces as the most commonly observed postprocedural complication following placement of fiducials under percutaneous CT guidance, which occurred in $45 \%$ of their cohort [19]. An alternative strategy was developed for placement of fiducials under bronchoscopic guidance with endobronchial ultrasound. Harley et al. reported this new technique with 43 consecutive patients who underwent fiducial placement using the endobronchial method [20]. Side effects reported were minimal with only one observed pneumothorax. Concordantly, pneumothorax risk at our institution dropped to zero following the transition to bronchoscopic placement. This technique not only has minimized morbidity but also affords an all-inclusive diagnostic approach in which the mediastinum can be staged, the primary tumor biopsied, and fiducials placed in a single procedure.

As we report here, a small but consistent decline in PFTs is noted in patients 1-year post-SBRT. Indeed, our understanding of pulmonary function changes following SBRT continues to evolve. Guckenberger et al. reviewed pretreatment and posttreatment PFTs in nearly 500 patients who were treated with SBRT for early-stage NSCLC [21]. They report statistically significant and progressive short-term ( $<6$ months) and long-term (6 to 24 months) pulmonary function declines of 3.6 and $6.8 \%$, respectively, averaged over all patients and pulmonary function parameters. Analogously, we note a $5.7 \%$ PFT decline averaged over all PFT values for the entire cohort at a median follow-up of approximately 1 year. An analysis of RTOG 0236 also found similar declines in FEV1 and $\mathrm{DL}_{\mathrm{CO}}$ at 2 years of 5.8 and $6.3 \%$, respectively [22]. Conversely, Bishawi et al. reported no significant changes in FEV1 or FVC following SBRT treatment [23]. More recently, the University of Torino reported prospective data of 30 patients showing significant reductions in FEV1 and $\mathrm{DL}_{\mathrm{CO}}$ following SBRT treatment at both 135 and 315 days of follow-up (3.21 and $6.32 \% ; 7.57$ and $14.85 \%$, respectively) [24]. The consensus from the literature as well as our institutional data demonstrates that SBRT treatment is associated with progressive-albeit small-PFT changes, which are of unclear clinical impact and may also be explained by the natural history of patients' underlying cardiopulmonary disease.

The close proximity of peripheral NSCLC tumors to the chest wall results in meaningful late toxicity following SBRT. In our cohort, we observed radiological evidence of rib fractures in those at-risk ribs in approximately one in five patients. Dunlap et al. reported toxicity data from 60 patients treated with SBRT to peripheral (defined as within $2.5 \mathrm{~cm}$ of the chest wall) primary or metastatic thoracic lesions [25]. Approximately $28 \%$ of patients developed late grade 3 or higher chest wall pain, but only five of these patients had documented radiological rib fractures. Similarly, retrospective data from Voroney et al. found that 11 of 42 patients developed chest wall pain following treatment of peripheral early-stage NSCLC with three-fraction SBRT (total dose of 54 to $60 \mathrm{~Gy}$ ) [26]. A total of nine patients were found to have rib fractures though two of these were asymptomatic. A Swedish retrospective review of 33 patients treated with SBRT to 45 Gy in 3 fractions identified 81 at-risk ribs defined as those receiving at least 21 Gy [27]. Of these at-risk ribs, 13 fractures $(16 \%)$ were found in seven patients. Undoubtedly, the chest wall should be considered a potential site for late SBRT-related toxicity, and this toxicity seems to manifest itself both as radiological rib fractures as well as non-specific chest wall pain. Despite the absence of ITV use in our study, rib fractures were not prominently reduced compared with historical data, though, given most respiratory motion is in the superior-inferior axis, this is not surprising. Ultimately, the optimal dose constraints for both rib and chest wall remain uncertain, 
and the appropriateness of these constraints are worrisome in the face of a potential detriment in tumor coverage and excess lung toxicity.

Our single institution retrospective review of patients with medically inoperable stage I NSCLC treated with SBRT demonstrates that comparable local control, locoregional control, and overall survival can be achieved with this novel fiducialbased technique. Limitations of the present study include its retrospective nature, the heterogeneity of SBRT fractionation schedules, and the small patient cohort. Additionally, due to its retrospective review, we were unable to correlate radiological rib fractures with clinical manifestations of chest wall syndrome. Several large-scale propensity-matched analyses have shown either equivalent or superior clinical outcomes with SBRT versus surgery [28, 29]. Although poor accrual has prevented definitive conclusions to be made from previous phase 3 studies of surgery versus SBRT in the operable population, a recent combined analysis of the STARS and ROSEL trials demonstrated a 3-year overall survival of 95 versus $79 \%$ $(p=0.037)$ in SBRT and surgery groups, respectively [30]. As evidence of SBRT treatment efficacy, limited toxicity, and patient preference continues to mount in the medically inoperable population, future trials including VALOR and SABRTooth will directly compare the merits of SBRT versus surgery in the operable population $[8,31]$.

\section{Conclusion}

Mediastinal evaluation, lesion biopsy, and fiducial placement by an interventional pulmonologist represent an all-inclusive and minimally morbid management strategy for the medically inoperable stage I NSCLC patient in preparation for SBRT treatment. Bronchoscopic fiducial placement clearly results in a lower risk of pneumothoraces requiring chest tube placement relative to CT-guided placement. There are observable PFT declines following SBRT treatment, but in this cohort, the only statistically significant decline was observed in $\mathrm{DL}_{\mathrm{CO}}$. The long-term follow-up reported here demonstrates that despite reduced treatment margins and lack of patient immobilization, this tumor tracking method leads to clinically comparable outcomes with other linac-based SBRT approaches. Nevertheless, the reduction in irradiation volume did not translate into clinically obvious improvements in toxicity. Future prospective trials should explore the optimal SBRT technique for treating stage I NSCLC.

Acknowledgments Malika Danner, MD, contributed to the development and maintenance of the institutional review board documentation. Anatoly Dritschilo, MD, provided general support and guidance for the study.

Authors' contributions This study was not supported by outside funding. All patients were treated by the same radiation oncologist and pulmonologist (BTC and EDA). JWL, SW, SK, NA, IP, MCR, BTC, and EDA all contributed to the study concept, design, and/or acquisition of data. JWL, SW, SK, NA, IP, MCR, and BTC completed the data collection. JWL contributed to the data analysis and the drafting of the manuscript. All authors contributed to revising and giving final approval to the submitted manuscript. All authors agree to be accountable for all aspects of the work including its accuracy and integrity. BTC has been identified as the guarantor of the paper.

\section{Compliance with ethical standards}

Funding source No funding support is associated with this study.

Conflict of interests Brian T. Collins, MD, is a paid speaker for Accuray Inc. Jonathan W. Lischalk, MD; Stephanie M. Woo, BA; Shaan Kataria, MD; Nima Aghdam, MD; Ima Paydar, MD; Michael C. Repka, MD; and Eric D. Anderson, MD, have no competing interests.

Ethical approval All procedures performed in studies involving human participants were in accordance with the ethical standards of the institutional and/or national research committee and with the 1964 Helsinki Declaration and its later amendments or comparable ethical standards. The article does not contain any studies with human or animal subjects performed by any of the authors. The local Health Research Institutional Review Board (IRB) approved this retrospective analysis of an established departmental treatment approach. Malika Danner, MD contributed to the development and maintenance of the IRB documentation.

Informed consent For this type of study, formal consent is not required.

Open Access This article is distributed under the terms of the Creative Commons Attribution 4.0 International License (http:// creativecommons.org/licenses/by/4.0/), which permits unrestricted use, distribution, and reproduction in any medium, provided you give appropriate credit to the original author(s) and the source, provide a link to the Creative Commons license, and indicate if changes were made.

\section{References}

1. Siegel RL, Miller KD, Jemal A (2016) Cancer statistics, 2016. CA Cancer J Clin 66(1):7-30

2. Howlader N, Noone AM, Krapcho M, Garshell J, Miller D, Altekruse SF, et al. (2015) SEER Cancer Statistics Review, 19752012, National Cancer Institute

3. Jemal A, Bray F, Center MM, Ferlay J, Ward E, Forman D (2011) Global cancer statistics. CA Cancer J Clin 61(2):69-90

4. Silvestri GA, Alberg AJ, Ravenel J (2009) The changing epidemiology of lung cancer with a focus on screening. BMJ 339:b3053

5. Chen Z, Fillmore CM, Hammerman PS, Kim CF, Wong KK (2014) Non-small-cell lung cancers: a heterogeneous set of diseases. Nat Rev Cancer 14(8):535-546

6. National Lung Screening Trial Research T, Aberle DR, Adams AM, Berg CD, Black WC, Clapp JD, et al. (2011) Reduced lung-cancer mortality with low-dose computed tomographic screening. N Engl J Med 365(5):395-409

7. Moyer VA (2014) Force USPST. Screening for lung cancer: U.S. Preventive Services Task Force recommendation statement. Ann Intern Med 160(5):330-338 
8. Ricardi U, Badellino S, Filippi AR (2015) Stereotactic body radiotherapy for early stage lung cancer: history and updated role. Lung Cancer 90(3):388-396

9. Wisnivesky JP, Bonomi M, Henschke C, Iannuzzi M, McGinn T (2005) Radiation therapy for the treatment of unresected stage I-II non-small cell lung cancer. Chest 128(3):1461-1467

10. Timmerman R, Paulus R, Galvin J, Michalski J, Straube W, Bradley J, et al. (2010) Stereotactic body radiation therapy for inoperable early stage lung cancer. JAMA 303(11):1070-1076

11. Chen VJ, Oermann E, Vahdat S, Rabin J, Suy S, Yu X, et al. (2012) CyberKnife with tumor tracking: an effective treatment for highrisk surgical patients with stage I non-small cell lung cancer. Front Oncol 2:9

12. Collins BT, Erickson K, Reichner CA, Collins SP, Gagnon GJ, Dieterich S, et al. (2007) Radical stereotactic radiosurgery with real-time tumor motion tracking in the treatment of small peripheral lung tumors. Radiat Oncol 2:39

13. Unger K, Ju A, Oermann E, Suy S, Yu X, Vahdat S, et al. (2010) CyberKnife for hilar lung tumors: report of clinical response and toxicity. J Hematol Oncol 3:39

14. Brown WT, Wu X, Fayad F, Fowler JF, Amendola BE, Garcia S, et al. (2007) CyberKnife radiosurgery for stage I lung cancer: results at 36 months. Clin Lung Cancer 8(8):488-492

15. Brown WT, Wu X, Fayad F, Fowler JF, Garcia S, Monterroso MI, et al. (2009) Application of robotic stereotactic radiotherapy to peripheral stage I non-small cell lung cancer with curative intent. Clin Oncol 21(8):623-631

16. Timmerman R, Hu C, Michalski J, Straube W, Galvin J, Johnstone D (2014) Long-term Results of RTOG 0236: A phase II trial of stereotactic body radiation therapy (SBRT) in the treatment of patients with medically inoperable stage I non-small cell lung cancer. 2014 American Society for Radiation Oncology (ASTRO) 56th Annual Meeting. Tuesday, September 16, 2014, 7:00 a.m. Pacific time

17. Matsuo Y, Takayama K, Nagata Y, Kunieda E, Tateoka K, Ishizuka $\mathrm{N}$, et al. (2007) Interinstitutional variations in planning for stereotactic body radiation therapy for lung cancer. Int J Radiat Oncol Biol Phys 68(2):416-425

18. Hayashi S, Tanaka H, Hoshi H (2015) Imaging characteristics of local recurrences after stereotactic body radiation therapy for stage I non-small cell lung cancer: evaluation of mass-like fibrosis. Thorac Cancer 6(2):186-193

19. Kothary N, Heit JJ, Louie JD, Kuo WT, Loo BW Jr, Koong A, et al. (2009) Safety and efficacy of percutaneous fiducial marker implantation for image-guided radiation therapy. J Vasc Int Radiol: JVIR 20(2):235-239

20. Harley DP, Krimsky WS, Sarkar S, Highfield D, Aygun C, Gurses B (2010) Fiducial marker placement using endobronchial ultrasound and navigational bronchoscopy for stereotactic radiosurgery: an alternative strategy. Ann Thorac Surg 89(2):368-373 discussion 73-4
21. Guckenberger M, Kestin LL, Hope AJ, Belderbos J, Werner-Wasik M, Yan D, et al. (2012) Is there a lower limit of pretreatment pulmonary function for safe and effective stereotactic body radiotherapy for early-stage non-small cell lung cancer? J Thorac Oncol: Off Publ Int Assoc Study Lung Cancer 7(3):542-551

22. Stanic S, Paulus R, Timmerman RD, Michalski JM, Barriger RB, Bezjak A, et al. (2014) No clinically significant changes in pulmonary function following stereotactic body radiation therapy for early-stage peripheral non-small cell lung cancer: an analysis of RTOG 0236. Int J Radiat Oncol Biol Phys 88(5):1092-1099

23. Bishawi M, Kim B, Moore WH, Bilfinger TV (2012) Pulmonary function testing after stereotactic body radiotherapy to the lung. Int J Radiat Oncol Biol Phys 82(1):e107-e110

24. Ferrero C, Badellino S, Filippi AR, Focaraccio L, Giaj Levra M, Levis M, et al. (2015) Pulmonary function and quality of life after VMAT-based stereotactic ablative radiotherapy for early stage inoperable NSCLC: a prospective study. Lung Cancer 89(3):350-356

25. Dunlap NE, Cai J, Biedermann GB, Yang W, Benedict SH, Sheng $\mathrm{K}$, et al. (2010) Chest wall volume receiving $>30$ Gy predicts risk of severe pain and/or rib fracture after lung stereotactic body radiotherapy. Int J Radiat Oncol Biol Phys 76(3):796-801

26. Voroney JP, Hope A, Dahele MR, Purdie TG, Franks KN, Pearson S, et al. (2009) Chest wall pain and rib fracture after stereotactic radiotherapy for peripheral non-small cell lung cancer. J Thorac Oncol: Off Publ Int Assoc Study Lung Cancer 4(8):1035-1037

27. Pettersson N, Nyman J, Johansson KA (2009) Radiation-induced rib fractures after hypofractionated stereotactic body radiation therapy of non-small cell lung cancer: a dose- and volume-response analysis. Radiother Oncol: J Eur Soc Ther Radiol Oncol 91(3): 360-368

28. Shirvani SM, Jiang J, Chang JY, Welsh JW, Gomez DR, Swisher S, et al. (2012) Comparative effectiveness of 5 treatment strategies for early-stage non-small cell lung cancer in the elderly. Int J Radiat Oncol Biol Phys 84(5):1060-1070

29. Verstegen NE, Oosterhuis JW, Palma DA, Rodrigues G, Lagerwaard FJ, van der Elst A, et al. (2013) Stage I-II non-smallcell lung cancer treated using either stereotactic ablative radiotherapy (SABR) or lobectomy by video-assisted thoracoscopic surgery (VATS): outcomes of a propensity score-matched analysis. Ann Oncol: Off J Eur Soc Med Oncol/ ESMO 24(6):1543-1548

30. Chang JY, Senan S, Paul MA, Mehran RJ, Louie AV, Balter P, et al. (2015) Stereotactic ablative radiotherapy versus lobectomy for operable stage I non-small-cell lung cancer: a pooled analysis of two randomised trials. Lancet Oncol 16(6):630-637

31. Shaverdian N, Wang PC, Steinberg M, Lee P (2015) The patient's perspective on stereotactic body radiation therapy (SBRT) vs. surgery for treatment of early stage non-small cell lung cancer (NSCLC). Lung Cancer 90(2):230-233 